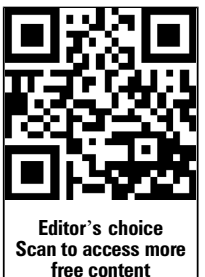

free content

- Additional material is published online only. To view please visit the journal online (http://dx.doi.org/10.1136/ oemed-2013-101651)

${ }^{1}$ Western Australian Institute for Medical Research, University of Western Australia, Perth, Western Australia, Australia

${ }^{2}$ School of Public Health, University of Sydney, Sydney, New South Wales, Australia ${ }^{3}$ Department of Epidemiology and Preventive Medicine, Monash University, Melbourne, Victoria, Australia

\section{Correspondence to} Dr Renee N Carey, Western Australian Institute for Medical Research, University of Western Australia, Ground Floor, B Block, Sir Charles Gairdner Hospital, Hospital Avenue, Nedlands, WA 6009, Australia; renee.carey@waimr.uwa.edu.

Received 6 June 2013 Revised 19 September 2013 Accepted 9 October 2013

Published Online First

24 October 2013

\title{
Estimated prevalence of exposure to occupational carcinogens in Australia (2011-2012)
}

\author{
Renee N Carey, ${ }^{1}$ Timothy R Driscoll, ${ }^{2}$ Susan Peters, ${ }^{1}$ Deborah C Glass, ${ }^{3}$ Alison Reid, ${ }^{1}$ \\ Geza Benke, ${ }^{3}$ Lin Fritschi ${ }^{1}$
}

\section{ABSTRACT}

Background and objectives Although past studies of workplace exposures have contributed greatly to our understanding of carcinogens, significant knowledge gaps still exist with regard to the actual extent of exposure among current workers, with no routinely collected population-based data being available in most countries. This study, the Australian Work Exposures Study (AWES), aimed to investigate the current prevalence of occupational exposure to carcinogens. Methods A random sample of men and women aged between 18 and 65 , who were currently in paid employment, were invited to participate in a telephone interview collecting information about their current job and various demographic factors. Interviews were conducted using a web-based application (OccIDEAS). OccIDEAS uses the expert exposure method in which participants are asked about their job tasks and predefined algorithms are used to automatically assign exposures. Responses were obtained from 5023 eligible Australian residents, resulting in an overall response rate of $53 \%$.

Results 1879 respondents (37.6\%) were assessed as being exposed to at least one occupational carcinogen in their current job. Extrapolation of these figures to the Australian working population suggested 3.6 million $(40.3 \%)$ current workers could be exposed to carcinogens in their workplace. Exposure prevalence was highest among farmers, drivers, miners and transport workers, as well as men and those residing in regional areas.

Conclusions This study demonstrates a practical, webbased approach to collecting population information on occupational exposure to carcinogens and documents the high prevalence of current exposure to occupational carcinogens in the general population.

\section{INTRODUCTION}

Over 165 occupational carcinogens have been identified by the International Agency for Research on Cancer (IARC). ${ }^{1}$ In addition, 18 occupations (eg, painter) or exposure circumstances (eg, firefighting) have been associated with an excess risk of cancer. Exposures to these carcinogens contribute significantly to the burden of cancer, with a recent study in the UK estimating that $8.2 \%$ of all cancers in men and $2.3 \%$ in women were related to occupation. $^{2}$ Occupational exposures are of particular concern as, unlike lifestyle exposures such as diet and alcohol, they are encountered involuntarily and are commonly of greater magnitude than exposures in the general environment. ${ }^{3}$ Such exposures are

\section{What this paper adds}

- There exist significant knowledge gaps with regard to the extent of occupational exposure to carcinogens among workers in many countries.

- Information regarding the prevalence of occupational exposure is necessary in order to target prevention efforts and understand patterns of exposure, as well as to estimate the burden of occupational cancer arising from these exposure.

- This study provides evidence that the overall prevalence of exposure to occupational carcinogens among Australian workers is of concern.

- Patterns of exposure differ across occupational and demographic groups, with those most at risk of exposure being male workers residing in regional areas.

also more likely to be amenable to risk reduction by implementing controls in the workplace rather than by changing individual behaviour. ${ }^{4}$

Past studies of workplace exposures have contributed greatly to our understanding of carcinogens and cancer aetiology. ${ }^{5}$ However, significant knowledge gaps still exist regarding the actual extent of exposure among workers in many countries, including Australia, as well as the trends in exposure over time. National exposure surveillance is not widely carried out in Australia, meaning that routinely collected population-based data concerning the prevalence and extent of exposure are not available. $^{6}$ Those studies that have investigated the prevalence of occupational exposure have generally focused on specific exposures (eg, benzene) ${ }^{7}$ or particular high-risk industries (eg, aluminium production industry), ${ }^{8}$ rather than investigating a range of occupational exposures across the whole working population. This means that the carcinogens encountered by workers in other industries (eg, prevalence of diesel exposure among farmers) and from unstudied carcinogenic agents have likely been underestimated. ${ }^{9}$ Additionally, many studies have relied on job title alone as an indicator of exposure, despite the probability of considerable variability in exposure within the same job title or occupation. ${ }^{10}$ 
In the USA, national occupational exposure data based on site visits to industrial facilities are available through the National Occupational Exposure Survey ${ }^{11}$; however, these data have not been updated since 1990. In addition, national exposure databases using the CARcinogen EXposure (CAREX) model are available in Canada, ${ }^{12}$ Finland $^{13}$ and Costa Rica. ${ }^{14}$ The extent to which these exposure assessments can be applied to workers in other countries is unclear, particularly where the exposure circumstances are clearly different. For example, estimates of solar ultraviolet radiation exposure obtained from Finland ${ }^{15}$ are likely to result in an underestimate of exposure when applied to Australia. In addition, the carcinogenic agents to which workers may feasibly be exposed vary between countries, with differences in, for example, manufacturing processes and legislation concerning the use of certain chemicals.

An alternative, more standardised exposure assessment method that may be used in large-scale, community-based studies is the job exposure matrix (JEM). These matrices assign exposures based on a cross tabulation of job titles and agents, with the measure of exposure being dichotomous (ever vs never exposed) or ordinal (categories of exposure). ${ }^{16}$ A quantitative JEM (assigning levels of exposure) has also recently been developed for use in community-based studies, ${ }^{17} 18$ although this may not be applicable to Australia. Further, a limitation of JEMs is that they typically allocate the same assessment to all workers with the same job title, ${ }^{19}$ despite the fact that exposures may vary widely between workers. ${ }^{20}$

Large-scale surveys covering the entire working population may therefore be necessary to gain a more complete view of the prevalence of occupational exposures. ${ }^{21}$ A number of such surveys have been carried out in countries including the UK, ${ }^{22}$ South Korea $^{23}$ and New Zealand, ${ }^{9}$ as well as the ongoing European Working Conditions Survey which collects data from workers across Europe. ${ }^{24}$ These surveys generally use similar methodology: interviewing workers from the general population about their work environment and collecting information about categories of exposure (eg, 'chemical substances', 'smoke/dust') rather than specific agents. In Australia, the National Hazard Exposure Worker Surveillance (NHEWS) survey was carried out in $2008 .^{25}$ NHEWS collected data from 4500 Australian workers and found that $39 \%$ were exposed to airborne hazards $^{26}$ and $37 \%$ to chemicals including detergents, organic solvents and disinfectants. ${ }^{27}$ However, the survey targeted workers in predetermined priority industries, meaning that these results are not representative of exposures experienced by the general Australian working population.

In addition, the exposure assessments were based on selfreport to open-ended questions, and thus the extent to which the results reflect the true prevalence of exposure among those who took part is unknown. While workers can self-report tasks or activities that they commonly undertake with reasonable accuracy, the ability of participants to accurately self-report specific exposures varies with the agent of interest and, more importantly, there is likely to be bias due to rumination by subjects with the disease. ${ }^{28} 29$ They may also be unaware of exposures, ${ }^{30}$ and generally have no objective standard against which to judge their own exposures and working conditions. ${ }^{28} 31$

A more objective method is expert assessment, whereby experts (typically occupational hygienists and physicians) make an assessment based on a review of an individual's job history in combination with the published literature, available exposure measurements, and their own experience and knowledge. ${ }^{32}$ Expert assessment is thought to be the most accurate and credible exposure assessment method for large scale studies, ${ }^{16}$ although the process has been described as a 'black box' whereby it can be difficult to determine how an exposure assessment has been arrived at. ${ }^{32}$ This may be overcome by the use of an automated expert assessment system which makes the assessment process more transparent and consistent. Moreover, the automated assessment makes it possible to assess a wide range of occupational exposures in the general population in an efficient way. ${ }^{32}$

The current study therefore used an automated expert assessment method (OccIDEAS) to gain a complete view of the current prevalence of exposure to carcinogens among Australian workers, focusing on those agents most relevant to Australian working conditions.

\section{METHODS}

\section{Study population}

The Australian Work Exposures Study (AWES) was a crosssectional telephone survey investigating the prevalence of current occupational exposure to 38 known or probable carcinogens among Australian workers (table 1). These carcinogens were prioritised according to three criteria: evidence of carcinogenicity (exposures classified as group 1 or 2A) according to IARC; use in occupational circumstances; and evidence of use in Australian industry. ${ }^{33}$ Ethics approval for this study was obtained from the (redacted for review) human research ethics committee of the University of Western Australia.

The sample for this study was randomly selected from a list of approximately 6 million Australian households supplied by a commercial survey sampling firm. This list, comprising addresses and telephone numbers, was sourced from various public domain directories, including but not limited to telephone directories. Both landline and mobile phone numbers were included, and the sample was stratified to reflect the approximate distribution of the Australian workforce by state and territory, as reported by the Australian Bureau of Statistics (ABS) Labour Force Survey from March 2011. ${ }^{34}$

Within these households, all Australian residents aged between 18 and 65 and currently in paid employment were eligible to participate. Respondents with insufficient English speaking ability and those who were deaf or too ill to participate were excluded as ineligible. Both male and female workers were included; although as men have been found to be less likely to participate in scientific research than women, ${ }^{35}$ a modified interview request was utilised in which men were asked for in six out of seven phone calls. That is, after introducing themselves, the interviewer asked to speak to the person of the specified gender who fit the eligibility criteria (ie, aged between 18 and 65 and currently working). In the case where there was more than one such person, the interviewer asked to speak to the one who had the next birthday.

A total of 19896 households were telephoned during the course of this study (figure 1). No response was obtained after 10 different call attempts from 2452 households, while 10485 households were designated ineligible and 1936 refused to participate. Interviews were conducted with 5023 respondents, resulting in a response fraction (completed interviews/eligible and unknown households) of 53\% and a cooperation fraction (completed interviews/eligible households) of $72 \%$.

\section{Data collection}

All data were collected by trained interviewers using computerassisted telephone interviews. Oral informed consent was provided by all respondents. Demographic information, including age, gender, postcode of residence, country of birth, year of 
Table 1 The list of carcinogens as prioritised by Fernandez et $a l^{33}$

\begin{tabular}{|c|c|}
\hline Agent group & Agent \\
\hline Combustion products (3) & $\begin{array}{l}\text { Diesel engine exhaust } \\
\text { Environmental tobacco smoke } \\
\text { Polycyclic aromatic hydrocarbons (PAHs)* }\end{array}$ \\
\hline Inorganic dusts (2) & $\begin{array}{l}\text { Asbestos } \\
\text { Crystalline silica dust }\end{array}$ \\
\hline Organic dusts (2) & $\begin{array}{l}\text { Leather dust } \\
\text { Wood dust }\end{array}$ \\
\hline Metals (7) & $\begin{array}{l}\text { Arsenic and inorganic arsenic compounds } \\
\text { Beryllium and beryllium compounds } \\
\text { Cadmium and cadmium compounds } \\
\text { Chromium (VI) compounds } \\
\text { Cobalt metal and tungsten carbide } \\
\text { Inorganic lead compounds } \\
\text { Nickel compounds }\end{array}$ \\
\hline Radiation (4) & $\begin{array}{l}\text { Artificial ultraviolet radiation (UVA, UVB, UVC) } \\
\text { lonising radiationt } \\
\text { Radon- } 222 \text { and its decay products } \\
\text { Solar radiation }\end{array}$ \\
\hline $\begin{array}{l}\text { Other industrial chemicals } \\
\text { (19) }\end{array}$ & $\begin{array}{l}\text { Acid mists, strong inorganic } \\
\text { Acrylamide } \\
\alpha \text {-chlorinated toluenes } ¥ \\
\text { Benzene } \\
\text { 1,3-butadiene } \\
\text { Diethyl sulfate } \\
\text { Dimethyl sulfate } \\
\text { Epichlorhydrin } \\
\text { Ethylene oxide } \\
\text { Formaldehyde } \\
\text { Glycidol } \\
4,4^{\prime} \text {-methylenebis (2-chloroaniline) (MOCA) } \\
N \text {-nitrosodimethylamine and } \\
N \text {-nitrosodiethylamine } \\
\text { ortho-Toluidine (2-aminotoluene) } \\
\text { Polychlorinated biphenyls (PCBs)§ } \\
\text { Styrene-7,8-oxide } \\
\text { Tetrachloroethylene (perchloroethylene) } \\
\text { Trichloroethylene } \\
\text { Vinyl chloride }\end{array}$ \\
\hline Non-chemical agents (1) & Shiftwork that involves circadian disruption \\
\hline \multicolumn{2}{|c|}{ 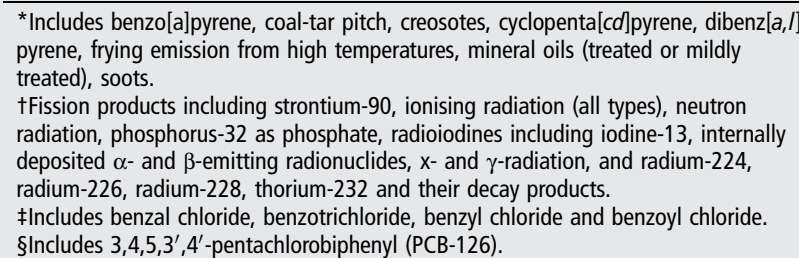 } \\
\hline
\end{tabular}

arrival in Australia, language spoken at home and education level was collected. Socioeconomic status and remoteness were determined by applying the ABS Socio-Economic Indexes for Areas Index of Relative Socio-economic Disadvantage ${ }^{36}$ and the Australian Standard Geographical Classification Accessibility/ Remoteness Index of Australia ${ }^{37}$ to the respondent's postcode of residence.

Basic job information was collected to determine whether the respondent's current job corresponded to one of the 13 predetermined categories of jobs which were not exposed to any of the 38 carcinogens. These categories included retail workers, customer service workers, carers, correctional services workers, and psychologists and social workers, as well as those on home duties. The other categories comprised white collar professionals and clerical workers, provided they did not travel or drive as part of their work; takeaway restaurant staff who were not involved in cooking duties; house cleaners, as opposed to cleaners working in other settings, as these workers were considered unlikely to use harsh chemicals; and early childhood or childcare workers, primary school teachers, and high school teachers not involved in art, science or technical subjects, in contrast to teachers involved in these three subject areas. The 2532 respondents whose job fitted into one of these categories were classified as unexposed and the interview considered complete. For the remaining 2491 respondents, more information regarding their current job was obtained, including job title, main tasks carried out in the job, industry of employment, hours worked per week and weeks worked per year.

Based on this job information, interviewers assigned respondents to one of 57 job specific modules (JSMs). Specific JSMs were completed by 2385 respondents. An appropriate JSM could not be determined for the remaining 106 respondents, and so a generic JSM was utilised in which open-ended questions were used to collect information about the respondent's day-to-day job tasks. All modules were delivered using OccIDEAS, a web-based tool which manages interviews and the exposure assessment process. ${ }^{32}$ Each full interview took approximately $15 \mathrm{~min}$.

Following the interviews, each of the jobs was coded according to the Australian and New Zealand Standard Classification of Occupations ${ }^{38}$ and the International Standard Classification of Occupations 1968. ${ }^{39}$ These codes were then categorised into 30 occupational groups, each of which were considered to contain occupations which were relatively homogeneous with regard to exposure to the 38 carcinogens investigated here (see online supplementary table 1 ). In deciding on these groups, reference was made to the job tasks outlined in the occupation definitions provided by the $\mathrm{ABS},{ }^{38}$ and the likely exposures that may result from those tasks. For example, 'funeral workers' were grouped with scientists as their tasks include the preparation of bodies for viewing, which may involve exposure to chemicals such as formaldehyde, other embalming fluids and disinfectants, similar to exposures that may be encountered by medical and science technicians.

\section{Exposure assessment}

The JSMs contained questions about the current completion of job tasks likely to entail exposure to the priority carcinogens, as established with reference to: published literature; reference texts $^{40}{ }^{41}$; various reports including IARC Monographs, ${ }^{1}$ CAREX reports ${ }^{12}$ and the National Toxicology Program's 12th Report on Carcinogens ${ }^{42}$; material safety data sheets; and expert knowledge. All JSMs were developed by a team including occupational hygienists and epidemiologists. Modules were only developed for those jobs considered to involve possible exposure to the priority carcinogens and which were reasonably prevalent in Australia. ${ }^{34}$

Each JSM included questions about the general working environment as well as specific tasks completed and, where appropriate, gathered information about the frequency of tasks, task method (eg, using a power sander vs sanding by hand), and any protective measures used (including ventilation, respiratory equipment, gloves, and other protective clothing). Questions focused on what respondents currently do in their job, asking, for example, 'Do you sand wood?' and 'What do you use to thin paints?'. Some task questions were used in more than one module; for example, welding questions appeared in 15 different JSMs including Construction and Mechanic. All questions were tailored to Australian industry and occupation conditions.

The generic JSM collected information about the tasks respondents commonly carry out in their jobs. These JSM 


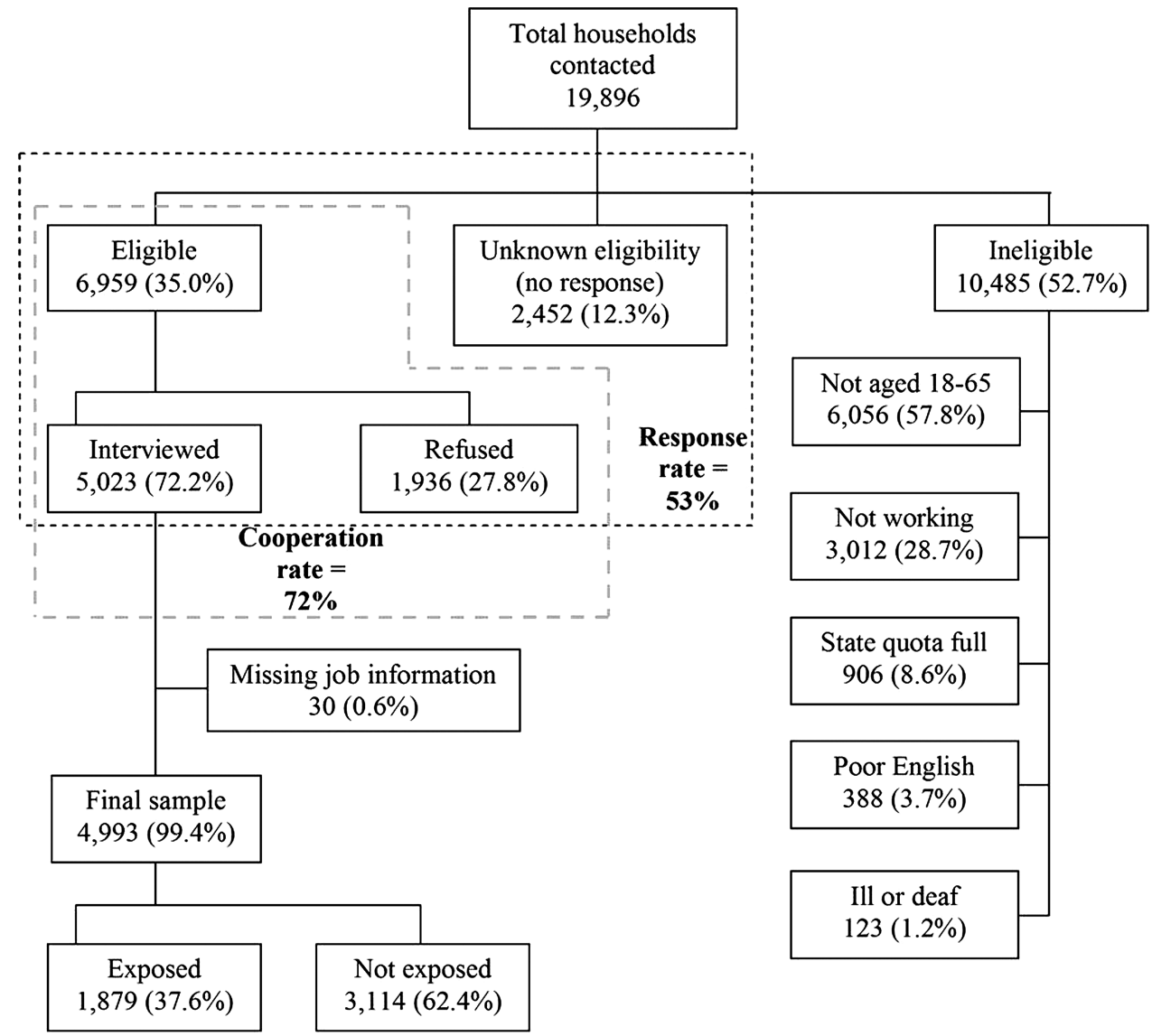

Figure 1 Response flow chart for the Australian Work Exposures Study (AWES) Sample, Australia, 2011-2012.

answers were then reviewed by two occupational hygienists (DG, SP), who assigned exposures based on the tasks reported and their expert opinion. For all other JSMs, OccIDEAS was used to provide automatic assessments of the probability (either 'no', 'possible' or 'probable') of exposure to each of the 38 carcinogens. Automatic assessments were based on predetermined rules developed on the basis of expert opinion and scientific literature, including, where relevant, exposure measurements. The rules were attached to and triggered by specific answers within the JSM. As an example of a simple rule, if someone answered that they frequently drove along major metropolitan roads, they would be assessed as being exposed to diesel engine exhaust. All automatic assessments were reviewed by project staff and changes to rules were made where appropriate. Any such changes were then applied to all assessments using that rule.

\section{Statistical analysis}

Statistical analyses were conducted using Stata V.12. ${ }^{43}$ Prevalence of exposure was defined as the proportion of respondents assessed as being exposed to at least one of the priority carcinogens in their current job, regardless of frequency, duration or level of exposure. A dichotomous measure of exposed or not exposed was used. ORs and 95\% CIs were estimated using logistic regression in order to explore which demographic variables were associated with exposure. Both unadjusted and adjusted models were estimated, with occupational group and all other included variables adjusted for in the latter analysis.

These assessments were then extrapolated with reference to the ABS Labour Force Survey ${ }^{34}$ to provide an estimate of how many workers in Australia are likely to be exposed to each of the priority carcinogens. Extrapolations were conducted separately by occupational group and were stratified by gender in order to account for potential exposure differences.

\section{RESULTS}

Of the 5023 completed interviews, 30 had missing job history information and were excluded from analysis. The demographic distribution of the remaining 4993 respondents (2766 male, 2227 female) was compared with the distribution in the Australian working population (aged 18 to 65) using Census 2011 data (see online supplementary table 2). ${ }^{44}$ Respondents were similar to the general population in terms of gender, education level, socioeconomic status and remoteness, as well as state of residence. However, respondents were significantly older, more likely to have been born in Australia, and less likely to speak a language other than English at home than the general population. The latter result was expected as it was a requirement of this study that respondents could speak sufficient English to complete the survey.

A total of 1879 respondents (37.6\%) were assessed as being probably exposed to at least one of the priority carcinogens. Including possible exposures altered this proportion only slightly $(n=1912,38.3 \%)$; the following analyses were restricted to probable exposures only. Possible exposures are outlined in online supplementary table 3 .

After controlling for occupation, respondents assessed as being probably exposed to at least one carcinogen were more likely to be male, to have completed a trade certificate and to reside in regional areas than were unexposed workers (table 2). 
Table 2 ORs and 95\% Cls for association between demographic characteristics and assessment of exposure in final sample

\begin{tabular}{|c|c|c|c|c|c|c|}
\hline Demographic characteristic & Exposed \% & Unexposed \% & Unadjusted OR & Unadjusted $95 \% \mathrm{Cl}$ & Adjusted OR* & Adjusted $95 \% \mathrm{Cl}$ \\
\hline \multicolumn{7}{|l|}{ Gender } \\
\hline Male & 78.0 & 41.8 & 1.00 & & 1.00 & \\
\hline Female & 22.0 & 58.2 & 0.20 & 0.18 to 0.23 & 0.34 & 0.27 to 0.41 \\
\hline \multicolumn{7}{|l|}{ Age } \\
\hline $18-34$ & 17.4 & 13.7 & 1.37 & 1.17 to 1.61 & 1.13 & 0.87 to 1.46 \\
\hline $35-54$ & 57.6 & 62.0 & 1.00 & & 1.00 & \\
\hline $55-65$ & 25.0 & 24.3 & 1.11 & 0.97 to 1.28 & 1.04 & 0.83 to 1.29 \\
\hline \multicolumn{7}{|l|}{ Country of birth } \\
\hline Australia & 80.7 & 78.9 & 1.00 & & 1.00 & \\
\hline Other & 19.3 & 21.1 & 0.89 & 0.77 to 1.03 & 1.07 & 0.85 to 1.35 \\
\hline \multicolumn{7}{|l|}{ Language at home } \\
\hline English & 98.2 & 98.0 & 1.00 & & 1.00 & \\
\hline Other & 1.8 & 2.0 & 1.10 & 0.72 to 1.68 & 0.92 & 0.49 to 1.73 \\
\hline \multicolumn{7}{|l|}{ Highest education level } \\
\hline High school or less & 40.6 & 34.9 & 1.00 & & 1.00 & \\
\hline Trade certificate or diploma & 37.9 & 21.9 & 1.49 & 1.29 to 1.71 & 1.33 & 1.04 to 1.69 \\
\hline Bachelor degree or higher & 21.5 & 43.2 & 0.43 & 0.37 to 0.49 & 0.84 & 0.66 to 1.08 \\
\hline \multicolumn{7}{|l|}{ State of residence } \\
\hline New South Wales & 31.9 & 36.1 & 1.00 & & 1.00 & \\
\hline Victoria & 25.6 & 24.0 & 1.21 & 1.04 to 1.40 & 1.00 & 0.78 to 1.27 \\
\hline Queensland & 19.9 & 17.1 & 1.31 & 1.11 to 1.55 & 1.08 & 0.82 to 1.42 \\
\hline Western Australia & 12.9 & 10.4 & 1.41 & 1.16 to 1.71 & 1.05 & 0.76 to 1.45 \\
\hline South Australia & 5.3 & 6.6 & 0.90 & 0.69 to 1.16 & 0.82 & 0.54 to 1.23 \\
\hline Australian Capital Territory & 1.0 & 2.9 & 0.40 & 0.24 to 0.65 & 0.89 & 0.45 to 1.77 \\
\hline Tasmania & 2.6 & 1.6 & 1.76 & 1.17 to 2.64 & 1.12 & 0.59 to 2.14 \\
\hline Northern Territory & 0.8 & 1.3 & 0.70 & 0.38 to 1.28 & 0.49 & 0.18 to 1.37 \\
\hline \multicolumn{7}{|l|}{ Socioeconomic status } \\
\hline Highest quintile & 21.1 & 31.1 & 1.00 & 1.00 & & \\
\hline Fourth & 23.1 & 26.1 & 1.31 & 1.11 to 1.54 & 0.89 & 0.68 to 1.16 \\
\hline Third & 22.8 & 19.0 & 1.77 & 1.49 to 2.10 & 1.06 & 0.79 to 1.41 \\
\hline Second & 20.9 & 15.1 & 2.03 & 1.70 to 2.43 & 1.01 & 0.74 to 1.38 \\
\hline Lowest & 12.1 & 8.7 & 2.05 & 1.66 to 2.54 & 1.30 & 0.92 to 1.84 \\
\hline \multicolumn{7}{|l|}{ Remoteness } \\
\hline Major city & 50.3 & 66.9 & 1.00 & 1.00 & & \\
\hline Inner regional & 32.4 & 24.1 & 1.78 & 1.56 to 2.03 & 1.32 & 1.04 to 1.66 \\
\hline Outer regional & 14.6 & 7.8 & 2.48 & 2.05 to 3.00 & 1.46 & 1.03 to 2.08 \\
\hline Remote/very remote & 2.7 & 1.2 & 2.95 & 1.93 to 4.53 & 1.88 & 0.89 to 3.98 \\
\hline
\end{tabular}

*Adjusted for occupational group and all other variables in model.

No differences were found in terms of country of birth or language most commonly spoken at home.

Significant differences in exposure prevalence were also found by occupational group. Among men, farmers, heavy vehicle drivers and miners were most likely to be exposed to at least one carcinogen (see online supplementary table 4), while among women, farmers, drivers and transport workers were most likely to be exposed (see online supplementary table 5). Extrapolation of these figures to the Australian working population revealed that approximately 2727000 men $(58.0 \%$; $95 \%$ CI 56.2 to 59.9 ) and 877100 women (20.6\%; $95 \%$ CI 18.9 to 22.3 ), or 3604100 workers overall $(40.3 \%$; 95\% CI 38.9 to 41.6), could be expected to be exposed to at least one of the priority carcinogens.

The most frequent exposure was solar radiation, with $37.0 \%$ of the Australian male working population and $7.9 \%$ of the female working population exposed (see tables 3 and 4). Diesel engine exhaust and environmental tobacco smoke were also common exposures, with over a million working men estimated to be exposed to each. In addition, more than $10 \%$ of the male working population was exposed to each of benzene, lead and silica. Many of the other occupational carcinogens had small numbers of exposed workers in our dataset (as indicated by the wide CIs) and so the extrapolations should be regarded with caution.

\section{DISCUSSION}

This study examined the current prevalence of exposure to occupational carcinogens among Australian workers. Overall, $37 \%$ of respondents were assessed as being exposed to at least one carcinogen, with exposures being more common among male workers, those who had completed a trade certificate and those residing in regional areas, after adjusting for occupation. These results are similar to those found in the NHEWS survey, where male workers were more likely to report being exposed to chemicals ${ }^{27}$ and airborne hazards, ${ }^{26}$ as well as the European Working Conditions Survey, where men were more likely to be exposed to 11 of the 13 physical risks studied. ${ }^{24}$

On extrapolation to the Australian working population, 3.6 million workers were estimated as being occupationally exposed 
Table 3 Proportion of final sample and Australian working population estimated to be occupationally exposed by carcinogenic agent, men

\begin{tabular}{|c|c|c|c|c|}
\hline Carcinogen* & Most common occupational groups & $\begin{array}{l}\text { Sample } \\
\text { n (\%) }\end{array}$ & $\begin{array}{l}\text { Population } \\
\text { n (\%) }\end{array}$ & $\begin{array}{l}\text { Population } \\
95 \% \mathrm{Cl} \dagger\end{array}$ \\
\hline Solar UVR & Farmer, animal/horticultural, painter & $963(34.8)$ & $1737500(37.0)$ & 35.2 to 38.8 \\
\hline Diesel engine exhaust & Farmer, heavy vehicle driver, miner & $796(28.8)$ & $1344500(28.6)$ & 26.9 to 30.3 \\
\hline ETS & Painter, plumber, hospitality & $589(21.3)$ & $1164000(24.8)$ & 23.2 to 26.4 \\
\hline Benzene & Farmer, animal/horticultural, automobile driver & $370(13.4)$ & $636440(13.5)$ & 12.3 to 14.8 \\
\hline Lead & Painter, vehicle worker, plumber & $295(10.7)$ & $502100(10.7)$ & 9.6 to 11.9 \\
\hline Silica & Miner, construction, engineer & $289(10.5)$ & $543390(11.6)$ & 10.5 to 12.9 \\
\hline Wood dust & Carpenter, painter, handyperson & $271(9.8)$ & $449470(9.6)$ & 8.6 to 10.8 \\
\hline Artificial UVR & Farmer, vehicle worker, metal worker & $247(8.9)$ & $391770(8.3)$ & 7.4 to 9.4 \\
\hline PAHs & Farmer, emergency worker, food service & $239(8.6)$ & $454160(9.7)$ & 8.6 to 10.9 \\
\hline Shiftwork $\ddagger$ & Nurse, miner, passenger transport & $203(7.3)$ & $396120(8.4)$ & 7.4 to 9.5 \\
\hline Chromium VI & Painter, metal worker, carpenter & $168(6.1)$ & $291930(6.2)$ & 5.3 to 7.1 \\
\hline Asbestos & Vehicle worker, emergency worker, miner & $138(5.0)$ & $251960(5.4)$ & 4.6 to 6.3 \\
\hline Formaldehyde & Carpenter, painter, emergency worker & $118(4.3)$ & $200150(4.3)$ & 3.6 to 5.1 \\
\hline Nickel & Metal worker, plumber, vehicle worker & $98(3.5)$ & $170840(3.6)$ & 3.0 to 4.4 \\
\hline lonising radiation & Health professional, miner, scientist & $74(2.7)$ & $127800(2.7)$ & 2.2 to 3.4 \\
\hline Trichloroethylene & Farmer, metal worker, plumber & $44(1.6)$ & $73570(1.6)$ & 1.2 to 2.1 \\
\hline Arsenic & Carpenter, office worker, heavy vehicle driver & $33(1.2)$ & $49750(1.1)$ & 0.8 to 1.5 \\
\hline Vinyl chloride & Emergency worker, machine operator & $19(0.7)$ & $40780(0.9)$ & 0.6 to 1.3 \\
\hline Ethylene oxide & Emergency worker, food factory, scientist & $22(0.8)$ & $46240(1.0)$ & 0.7 to 1.5 \\
\hline 1,3-butadiene & Emergency worker & $21(0.8)$ & $44650(1.0)$ & 0.7 to 1.5 \\
\hline Cadmium & Metal worker, vehicle worker, electrical worker & $13(0.5)$ & $20840(0.4)$ & 0.2 to 0.7 \\
\hline Nitrosamines & Metal worker, scientist & $8(0.3)$ & $14710(0.3)$ & 0.1 to 0.6 \\
\hline Acid mists & Machine operator, metal worker, engineer & $5(0.2)$ & $11060(0.2)$ & 0.1 to 0.5 \\
\hline
\end{tabular}

*Includes only those priority carcinogens with five or more workers exposed.

$+95 \% \mathrm{Cl}$ of the proportion.

‡Exposed to any one or more of seven shiftwork agents (light at night, phase shift, sleep disturbance, diet and chronodisruption, alcohol and chronodisruption, lack of physical activity, and vitamin $\mathrm{D}$ insufficiency).

ETS, environmental tobacco smoke; PAHs, polycyclic aromatic hydrocarbons; UVR, ultraviolet radiation.

to carcinogens. This represents approximately $40 \%$ of the Australian workforce. Exposures were not distributed evenly across occupational groups, with some groups having a much higher probability of exposure than others. For example, all of the heavy vehicle drivers and miners were estimated to be exposed, with the most frequent exposures being to diesel engine exhaust and silica, respectively, while among other groups, such as cleaners and food factory workers, much smaller proportions of workers were exposed. Exposures were not limited to those occupations traditionally thought to be at high risk, but were seen across all groups, including those generally considered to be unexposed. For example, $9 \%$ of office

Table 4 Proportion of final sample and Australian working population estimated to be occupationally exposed by carcinogenic agent, women

\begin{tabular}{|c|c|c|c|c|}
\hline Carcinogen* & Most common occupational groups & $\begin{array}{l}\text { Sample } \\
\text { n (\%) }\end{array}$ & $\begin{array}{l}\text { Population } \\
\text { n (\%) }\end{array}$ & $\begin{array}{l}\text { Population } \\
95 \% \mathrm{Cl} \dagger\end{array}$ \\
\hline Solar UVR & Farmer, handyperson, automobile driver & $137(6.2)$ & $334870(7.9)$ & 6.9 to 9.1 \\
\hline Diesel engine exhaust & Metal worker, heavy vehicle driver, miner & $127(5.7)$ & $255200(6.0)$ & 5.1 to 7.1 \\
\hline Shiftwork $\ddagger$ & Passenger transport, emergency worker, nurse & $104(4.7)$ & $192730(4.5)$ & 3.7 to 5.4 \\
\hline Benzene & Farmer, automobile driver, animal/horticultural & $101(4.5)$ & $217200(5.1)$ & 4.3 to 6.1 \\
\hline ETS & Construction, miner, heavy vehicle driver & $86(3.9)$ & $247360(5.8)$ & 4.9 to 6.8 \\
\hline lonising radiation & Health professional, scientist, nurse & $60(2.7)$ & $99940(2.3)$ & 1.8 to 3.0 \\
\hline PAHs & Farmer, emergency worker, food service & $58(2.6)$ & $104720(2.5)$ & 1.9 to 3.3 \\
\hline Silica & Construction, miner, farmer & $27(1.2)$ & $43510(1.0)$ & 0.7 to 1.5 \\
\hline Wood dust & Carpenter, farmer, printer & $20(0.9)$ & $28850(0.7)$ & 0.4 to 1.2 \\
\hline Formaldehyde & Animal/horticultural, health professional, health support & $16(0.7)$ & $29390(0.7)$ & 0.4 to 1.2 \\
\hline Lead & Miner, vehicle worker, emergency worker & $12(0.5)$ & $31040(0.7)$ & 0.4 to 1.2 \\
\hline Artificial UVR & Metal worker, farmer, scientist & $9(0.4)$ & $12670(0.3)$ & 0.2 to 0.6 \\
\hline Ethylene oxide & Electrical worker, health professional, health support & $7(0.3)$ & $12970(0.3)$ & 0.2 to 0.6 \\
\hline Trichloroethylene & Farmer, nurse, office worker & $6(0.3)$ & $8550(0.2)$ & 0.1 to 0.5 \\
\hline
\end{tabular}

*Includes only those priority carcinogens with five or more workers exposed.

$+95 \% \mathrm{Cl}$ of the proportion.

¥Exposed to any one or more of seven shiftwork agents (light at night, phase shift, sleep disturbance, diet and chronodisruption, alcohol and chronodisruption, lack of physical activity, and vitamin $D$ insufficiency).

ETS, environmental tobacco smoke; PAHs, polycyclic aromatic hydrocarbons; UVR, ultraviolet radiation. 
workers were estimated to be exposed to occupational carcinogens, with the most frequent exposure being diesel engine exhaust. Therefore it appears that even within jobs conventionally thought to be at low or no risk of exposure, workers may still perform tasks which entail some potential exposure, such as driving or visiting construction sites.

Solar radiation was the most frequent exposure overall, with over 2 million workers, or 23\%, exposed to significant solar radiation. This is somewhat lower than the estimate of sun exposure found in NHEWS (34\%). ${ }^{25}$ While it could be argued that this reflects an actual decrease in exposure over time, it is more likely a result of the differing exposure assessment methods used. In the NHEWS survey, respondents were asked directly about their exposure to predetermined categories of agents, ${ }^{27}$ including 'direct sunlight', whereas in the current study, task-based questions were used to determine exposure. This latter method can be argued to provide for more sensitive and specific estimates of prevalence, as it captures exposures that workers may be unaware of or unable to report while disregarding innocuous and noncarcinogenic exposures. ${ }^{45}$ It is however still possible that some exposures may have been missed by virtue of them not being included in the JSMs or rules, although every effort was made to preclude this possibility.

There are limitations to the approach used in this study, as exposure assessments were still based on self-report of tasks and may be subject to recall bias or social desirability constraints. ${ }^{46}$ However, given that respondents were only required to answer questions regarding their current job tasks, it is unlikely that these biases would have had a substantial effect on the data obtained. Whereas retrospective exposure assessment may be limited by the respondents' memory, job-specific questions have been shown to provide accurate information with regard to exposures in the current job. ${ }^{45}$ Another possible limitation of this study is the inclusion of only 38 carcinogens, which may have led to the exclusion of people exposed to carcinogens which were not on the list. The impact of this on the overall prevalence estimate obtained is however expected to be relatively minor, as the priority list included the common established carcinogens and anyone exposed to any of the less common carcinogens may well be exposed to one of the priority carcinogens, and therefore already have been taken account of in the estimate. We systematically identified the occupational carcinogens identified by IARC which were most likely to be present in Australia and found very low prevalences for some carcinogens, which suggests that we erred on the side of inclusivity.

The lower proportion of younger and migrant workers in the sample compared to the general population, and the resultant potential under-representation of particular occupations and industries, is another limitation of this study. This may have led to an underestimation of the prevalence of exposure. In addition, there is a potential bias arising from the relatively high number of refusals, non-responders and those with limited English language skills; however, the impact of this bias is unknown as we do not have any further information about nonparticipants. Further, the use of a cross-sectional study design, while providing for an accurate picture of current exposures, means that it is not possible to determine whether the exposures found here are likely to be enduring or only transitory.

\section{CONCLUSION}

Overall, this study represents an important addition to the scientific literature, providing comprehensive information regarding exposure to occupational carcinogens in a developed economy (Australia) which has not previously been available. As well as providing information on how many workers are likely to be exposed to carcinogens in the course of their work, the current study allows for an examination of the characteristics of exposed workers, finding exposures to be more common among male workers and those from regional areas. This may contribute to the health inequalities known to exist in the Australian population. ${ }^{47}$

Future research will use these data to estimate the lifetime risk of cancer likely to result from current occupational exposures and to investigate the theoretical impact on this risk of alternative exposure scenarios, such as closing certain industries or increasing the use of personal protective equipment. This will enable an assessment of how we might best intervene to reduce exposures and the subsequent risk of occupational cancer. The use of a population-based approach and consequent ability to capture exposures across a wide range of occupations, industries and demographic groups were particular strengths of this study, allowing for the investigation of exposures in all occupational groups, including those which have not traditionally been associated with carcinogenic exposures.

Acknowledgements The authors wish to acknowledge Renae Fernandez for her role in preparing the questionnaires for this study and Troy Sadkowsky for his technical assistance. The authors also thank Vicki Graham and Theresa Wilkes at the Survey Research Centre, Edith Cowan University, Western Australia for their assistance in the data collection for this manuscript.

Contributors RNC drafted this manuscript and conducted all statistical analyses under the direct supervision of $L F$, who directed the study and is responsible for its overall design. TRD, DCG, AR and GB were each involved in the design of the study and, together with SP, provided feedback on the draft of this manuscript. DCG, SP and $A R$ also contributed to the data analysis process.

Funding This work was supported by National Health and Medical Research Council (NHMRC) [grant 1003563] and the Cancer Council Western Australia.

Competing interests LF is supported by NHMRC and Cancer Council Western Australia fellowships.

Ethics approval University of Western Australian human research ethics committee.

Provenance and peer review Not commissioned; externally peer reviewed.

\section{REFERENCES}

1 International Agency for Research on Cancer. Monographs on the evaluation of carcinogenic risks to humans. Lyon: World Health Organization, 2013.

2 Rushton L, Hutchings SJ, Fortunato L, et al. Occupational cancer burden in Great Britain. Br J Cancer 2012;107:S3-7.

3 Weiderpass E, Boffetta P, Vainio H. Occupational causes of cancer. In: Alison MR. ed. The Cancer Handbook. NY: John Wiley \& Sons, 2007:443-52.

4 Macdonald W, Driscoll T, Stuckey R, et al. Occupational health and safety in Australia. Ind Health 2012;50:172-9.

5 Blair A, Marrett L, Freeman LB. Occupational cancer in developed countries. Environ Health-Glob 2011:10:S9.

6 Driscoll T. Review of Australian and New Zealand workplace exposure surveillance systems. Canberra: Commonwealth of Australia, 2006.

7 Glass DC, Gray CN. Estimating mean exposures from censored data: exposure to benzene in the Australian petroleum industry. Ann Occup Hyg 2001:45:275-82.

8 Benke G, Sim M, Fritschi L, et al. Beyond the job exposure matrix (JEM): the task exposure matrix (TEM). Ann Occup Hyg 2000;44:475-82.

9 Eng A, Mannetje AT, Cheng S, et al. The New Zealand Workforce Survey I: Self-reported occupational exposures. Ann Occup Hyg 2010;54:144-53.

10 Kauppinen T, Toikkanen J, Pukkala E. From cross-tabulations to multipurpose exposure information systems: A new job-exposure matrix. Am J Ind Med 1998:33:409-17.

11 Seta JA, Sundin DS, Pedersen DH. National occupational exposure survey field guidelines. Cincinnati, OH: Department of Health and Human Services, 1988.

12 CAREX Canada. Surveillance of environmental and occupational exposures for cancer prevention. Vancouver: CAREX Canada, 2013.

13 Kauppinen T, Toikkanen J, Pedersen D, et al. Occupational exposure to carcinogens in the European Union. Occup Environ Med 2000;57:10-18.

14 Partanen T, Chaves J, Wesseling C, et al. Workplace carcinogen and pesticide exposures in Costa Rica. Int J Occup Env Heal 2003;9:104-11.

15 Nurminen M, Karjalainen A. Epidemiologic estimate of the proportion of fatalities related to occupational factors in Finland. Scand J Work Environ Health 2001:27:161-213. 
16 McGuire V, Nelson LM, Koepsell TD, et al. Assessment of occupational exposures in community-based case-control studies. Annu Rev Publ Health 1998;19:35-53.

17 Peters S, Vermeulen R, Olsson A, et al. Development of an Exposure Measurement Database on Five Lung Carcinogens (ExpoSYN) for quantitative retrospective occupational exposure assessment. Ann Occup Hyg 2012;56:70-9.

18 Peters S, Kromhout H, Portengen L, et al. Sensitivity Analyses of Exposure Estimates from a Quantitative Job-exposure Matrix (SYN-JEM) for use in community-based studies. Ann Occup Hyg 2013;57:98-106.

19 Peters $\mathrm{S}$, Vermeulen R, Cassidy A, et al. Comparison of exposure assessment methods for occupational carcinogens in a multi-centre lung cancer case-control study. Occup Environ Med 2011;68:148-53.

20 Tielemans E, Heederik D, Burdorf A, et al. Assessment of occupational exposures in a general population: comparison of different methods. Occup Environ Med 1999;56:145-51.

21 Eng AJ. Workforce survey of occupational exposures and health effects in New Zealand. Wellington, NZ: Massey University, 2011.

22 Hodgson JT, Jones JR, Clarke SD, et al. 2005 Worker survey first findings report. London: Health and Safety Executive, 2005.

23 Park J, Lee N. First Korean working conditions survey: a comparison between South Korea and EU countries. Ind Health 2009;47:50-4.

24 Parent-Thirion A, Vermeylen G, van Houten G, et al. Fifth European working conditions survey. Luxembourg: Publications Office of the European Union, 2012.

25 Safe Work Australia. National Hazard Exposure Worker Surveillance (NHEWS) survey: 2008 results. Canberra: Commonwealth of Australia, 2009.

26 de Crespigny F, Safe Work Australia. National hazard exposure worker surveillance survey reports: exposure to dusts, gases, vapours, smoke and fumes and the provision of controls for these airborne hazards in Australian workplaces. Canberra: Commonwealth of Australia, 2010.

27 MacFarlane E, Benke K, Keegel T. National hazard exposure worker surveillance: chemical exposure and the provision of chemical exposure control measures in Australian workplaces. Canberra: Commonwealth of Australia, 2012.

28 Teschke K, Olshan AF, Daniels JL, et al. Occupational exposure assessment in case-control studies: opportunities for improvement. Occup Environ Med 2002;59:575-93.

29 Rodvall Y, Ahlbom A, Spannare B, et al. Glioma and occupational exposure in Sweden, a case-control study. Occup Environ Med 1996;53:526-32.

30 Fletcher $A C$, Engholm $G$, Englund $A$. The risk of lung-cancer from asbestos among Swedish construction workers - self-reported exposure and a job exposure matrix compared. Int J Epidemiol 1993;22:S29-35.
31 Fritschi L, Siemiatycki J, Richardson L. Self-assessed versus expert-assessed occupational exposures. Am J Epidemiol 1996;144:521-7.

32 Fritschi L, Friesen MC, Glass D, et al. OccIDEAS: retrospective occupational exposure assessment in community-based studies made easier. J Environ Public Health 2009. http://dx.doi.org/10.1155/2009/957023

33 Fernandez RC, Driscoll TR, Glass DC, et al. A priority list of occupational carcinogenic agents for preventative action in Australia. Aust NZ J Public Health 2012;36:111-15.

34 Australian Bureau of Statistics. Labour Force Australia. Canberra: Australian Bureau of Statistics, 2011.

35 Galea S, Tracy M. Participation rates in epidemiologic studies. Ann Epidemiol 2007:17:643-53.

36 Australian Bureau of Statistics. Socio-economic Indexes for Areas 2006. Canberra: Australian Bureau of Statistics, 2008.

37 Australian Bureau of Statistics. Australian standard geographical classification. Canberra: Australian Bureau of Statistics, 2011

38 Australian Bureau of Statistics. Australian and New Zealand standard classification of occupations. 1st edn. Canberra: Australian Bureau of Statistics, 2006

39 International Labour Office. International standard classification of occupations, Revised Edition 1968. Geneva: International Labour Office, 1969.

40 Burgess WA. Recognition of health hazards in industry: a review of materials and processes. New York: Wiley, 1995

41 Stellman JM. Encyclopaedia of occupational health and safety. Geneva: International Labour Office, 1998.

42 National Toxicology Program. Report on Carcinogens (RoC) 12. NC: US Department of Health and Human Services, 2011.

43 StataCorp. Stata Statistical Software: Release 12. TX: StataCorp LP, 2011.

44 Australian Bureau of Statistics. Census of population and housing. Canberra: Australian Bureau of Statistics, 2011.

45 Parks CG, Cooper GS, Nylander-French LA, et al. Comparing questionnaire-based methods to assess occupational silica exposure. Epidemiology 2004; 15:433-41.

46 Lenderink $A F$, Zoer I, van der Molen HF, et al. Review on the validity of self-report to assess work-related diseases. Int Arch Occup Environ Health 2012; 85:229-51

47 Turrell G, Mathers C. Socioeconomic inequalities in all-cause and specific-cause mortality in Australia: 1985-1987 and 1995-1997. Int J Epidemiol 2001:30:231-9. 